International Business Management 13 (5): 168-180, 2019

ISSN: $1993-5250$

(C) Medwell Journals, 2019

\title{
Using Quality Circles Technique to Eliminate the Defects and their Costs: A Case Study
}

\author{
${ }^{1}$ Hameed Ali Saleh and ${ }^{2}$ Aubaid Khayon Ali Alkhafaji \\ ${ }^{1}$ Department of Accounting, Al-Isra' a University College, Baghdad, Iraq \\ ${ }^{2}$ Department of Accounting, Al-Bayan University, Baghdad, Iraq \\ aubid.k@albayan.edu.iq
}

\begin{abstract}
The research aims to identify defects and their causes by using the quality circles through check lists to collect and analyze the production data and develop appropriate solutions to quality and cost reduction of products. The defects were classified and analyzed according to, their importance and causes. The research describes a case study of quality circles technique in the Iraqi automobile industry which illustrates the effectiveness of this technique. The research found that employees were the most influential factor in low quality of the product and consequent increase in costs. The product component's contribution to the total defects was low. While the proportion of contribution of the working methods was very small percentage of the total defects. Further, the contribution of the machines and equipment was relatively the least effective factors in the occurrence of product defects.
\end{abstract}

Key words: Cost accounting, cost management, management accounting, quality management and quality circle, contribution, technique

\section{INTRODUCTION}

In recent years there has been an increasing awareness of the need to adopt and apply quality management concepts to meet the challenges associated with competition, after the focus was on free trade of goods to flow freely among the world markets. Companies have been encouraged to apply these concepts in their manufacturing, assembly and service operations to maintain an acceptable level of quality to their products at low costs. The quality circles technique as one of these crucial quality management concepts is considered a contemporary technique that focuses on human resources development and profitability and contributes to a better understanding of the nature of work's problems. This technique is applied from the bottom to the top to help solving problems or preventing their occurrence.

Research background: The background of research deals with the problem, objectives, importance, hypothesis and methods of research as follows:

Problem of research: Many manufacturing companies have been suffering from the quality problems represented by the products which do not meet the intended expectations of the use and the high cost of re-work. Thus, this leads to negative effects on performance of the product. Through the field observations in the car production factories of the general company for the automobile industry and the access to the check lists for each product during the month of July, 2018 , it was noted that a number of product defects had increased with high cost assessment represented by the time allocated for the examination. Hence, the problem of research arises through the following two questions: does the factory management adopt the employee participation technique in problem-solving by the use of quality circles technique? Does the factory management have a clear perception of the causes of the defects?

Objectives of research: The overall objective of research is to identify the role of quality circles in improving the quality of production, reducing costs, increasing participation and communication among employees and management. This overall objective is achieved by the following sub-objectives: to build an integrated theoretical framework for the quality circles technique that explains its features, objectives, advantages and mechanisms. To identify the extent to which the quality circles technique can be applied in industrial projects. To identify the employee's self-development during research by allowing them to disclose their abilities to participate and communicate with each other and with management.

Corresponding Author: Aubaid Khayon Ali Alkhafaji, Department of Accounting, Al-Bayan University, Baghdad, Iraq, aubid.k@albayan.edu.iq 
Importance of research: This research is considered an attempt to shed light on the role of quality circles in eliminating the conflict related to the productivity, quality and cost by preventing or reducing defects in product outputs as well as preventing or reducing spoilage in its inputs. The importance of research lies in the fact that:

It sheds light on quality circles that focus on human resources development and profitability. It creates a better understanding of the nature of quality circles because it is an approach applied from bottom-to-top to help solving production problems, or preventing them from occurrence. It helps to identifying the influencing causes on quality from the entry of components of the product to the logistic department until the ending stage of production line. It contributes to improving the quality level, reducing defects or mistakes and delivery the product to the sales yards on the specified time. It is a significant attempt to apply the quality circles technique in the car production industry. Thus, it provides the quality control department with the quality circles technique and its tools to analyze the causes of spoilage during assembly operations in order to avoid them.

Hypothesis of research: The research is based on one main hypothesis. This hypothesis states that "the use of quality circles technique in accordance with the scientific and practical mechanisms has positive implications for reducing costs and improving product quality".

Literature review: This research briefly discusses quality circles technique and its uses in improving product quality and reducing its costs.

Development of quality circles: The quality circles were first established in Japan in 1962 and the name of "Kaoru Ishikawa: was associated with these circles with the coordination and support of the Japanese Federation of Scientists and Engineers. The first "circle" formed a small group of employees whose purpose was to identify and solve their business problems at Nippon Telecommunication company. The idea of the true father Ishikawa soon came to be accepted by Japanese companies and was adopted in over (35) companies during the first year. By the year (1978), the number of quality circles increased to be more than 1 million circles, comprising more than 10 million Japanese workers. Thus, the quality circles were spread and their application expanded in Eastern Asian countries to reach more than 20 million circles in China. Since, the early use of the quality circles in 1974 at the Lockhead Aerospace and
Rocket Science Company, the number of quality circles in the United States of America was grown to be more than $(25,000)$ circles (Kaplana and Hymavathi, 2013).

The success achieved by the companies in Japan as a result of increased worker participation was a response to persistent problems of qualitative and productive control at the expense of American companies was due to two reasons:

First: Quality circles essentially form as a process for developing staff with normal levels and the organizational aspect is given secondary importance on the contrary in both Europe and America.

Second: The research accompanying the quality circles in Japan is done as an internal process (within the company) while in the United States and Europe it is given to external consulting agencies (Shantanu and Kulkarni, 2013).

Concept of quality circles: Most of the staffs of an organization have the capacity to address the positions they face in their work in a creative manner. This concept assumes that workers have mentality, so, it is necessary to give them a chance to take advantage of their mental abilities by making them share a degree of responsibility. Generally, Blocher et al. (2010) defined quality circles as "a small group of employees from the same work area that meet regularly to identify and solve work-related problems and to implement and monitor solutions to the problems". This definition considers quality circles as a small group of workers who meet together regularly to identify and analyze problems related to quality, cost and make corrective actions to those problems with a view to improve product performance.

Shantanu and Kulkarni (2013) defined quality circle as "a small group of (6-12) staff members who meet regularly and voluntarily to discuss the improvements in their field of work, identity and train themselves in problem-solving techniques". The concept of quality circles emphasizes that a person who actually performs his or her job is the one who knows his/her job best due to his/her specialty and experience. This orientation provides workers with the opportunity to perform effectively, coordinate activities of the organization and ensure a significant change in the working environment between staff and the management of the organization through the participation of regular-level employees to perform new ideas. The quality circles are considered a method by which the management of organization focuses on quality and adopts the principle of participation for all members aiming at success through the achievement of 
Table 1: Comparison aspects of quality circles and work teams (Welekar and Kulkarni, 2013)

\begin{tabular}{lll}
\hline Comparison elements & Teams of quality circles & Work teams \\
\hline Orientation & Performance orientation & Identify the problem/project \\
Time frame & Determined by the members of the circle & Determined by the management \\
Nature of the group & Homogeneous & Heterogeneous \\
Communication & From bottom to top & From top to bottom \\
The field & The organization is linked to the problems of individuals & Based on management objectives \\
Required experience & Specific process & Non-independence of work or project \\
Technical style & Creative & It is often traditional \\
Dependence on management & Independent & Part of management function \\
Group size & Usually small & Variety, depend on work \\
Decisions & Be unanimous and presented to the executioners & Taken by the responsible leader and \\
& & the purpose is associated with the position \\
Official training & The training is formal and regular & No need for a specific training
\end{tabular}

benefit for both the employees and the organization (Chaudhary and Yadav, 2012). Shireen (2014) also, believes that the quality circle is a technique for increasing productivity and the involvement of management in solving technical and non-technical problems that occur during the course of work and the formulation of their solutions.

From the previous definitions, it can be said that quality circle is a technique used to generate ideas, solve problems in ways to improve quality, reduce costs or enhance performance. It also, provides an infrastructure for increasing the effectiveness and efficiency of activities based on their own potential for a group of employees who perform similar works for the purpose of reinforcing the position of the product for the customer.

Characteristics of quality circles: Kaplana and Hymavathi (2013) discussed the basic characteristics of quality circles such as:

Group of volunteers: A volunteer group of employees, to be joined by members according to, their wills without any pressure.

Group size: The size of group forming the circle is usually about (6-12) members coming from a particular area of work.

Group meetings: Group members meet regularly in time periods to discuss work problems and meet during normal working hours, usually the end of the working day. The meeting time is determined in advance in consultation with the director of the group.

Special agenda: Each circle has its own agenda with its own expressions and tools used to identify and select its own problems, to make recommendations for solving them for the purpose of improving institutional work.

Comparison of quality circles and work teams: The quality circles teams and work teams can be distinguished using the comparison element as shown in Table 1 .
Mechanism of quality circles technique: The quality circles technique is a process that includes a set of sequential steps, discussed by Gaikwad and Gaikwad (2009) such as:

Identification of the problem: The members of the circle should identify the problems to be resolved by preparing a list of problems.

Selection of the problem: Members of the circle would then make the preferences and choose the first priority problem.

Analysis of the problem: The problem is then categorized and analyzed using the basic problem solving techniques like brainstorming technique and Barreto technique, etc.

Finding alternative solutions: Identification of the causes of the problem helps to find various alternative solutions.

Choosing the most appropriate solution: The best solution is chosen among the solutions provided by closely following the feasibility and cost, of implementation.

Preparing a plan of action: Members prepare a plan of action to be implemented for an optimal solution such as implementation field, date and time.

Management approval: Members provide the best solution and plan of action before obtaining approval of the management.

Implementation and follow-up: Management assesses the solution provided before implementation and may also consider correcting the path.

Objectives of the quality circles: Quality circles are the appropriate means to use and apply an approach that avoids defects rather than their occurrence. The objectives of the quality circle are ranked by Abo-Alhol et al. (2006) according to their importance such as follows: 
Table 2: Principles of quality

\begin{tabular}{lll} 
The term in Japanese language & Meaning of the synonym & Meaning in English language \\
\hline SERI & Sort & The distinction disposal of unwanted \\
SEITON & Regulate & Save/appropriate arrangement for things to be easy to use \\
SEISO & Sweep & Hygiene/hy giene consideration \\
SEIKETSU & Purity & Pattem style/standard setting to improve the productive working environment \\
SHIT SUKE & Self-tuning & Discipline/commitment to training \\
\hline
\end{tabular}

- Increase of quality

- Reduction of the number of damaged parts or units or defects and disposal of unnecessary activities

- Increase of productivity

- Increase of staff participation in decision-making

- Making the staff feel important

- Increase of communication between staff and management

- Allowing them to use intelligence skills and the ability to regenerate

- The ability to compete in the domestic and global markets

- Overcoming impediments to the organizational structure

- Establishing and improving a working environment for staff, so that, they can coexist in a positive spirit

Organizational structure as a basic element of the quality circle: To achieve performance efficiently and effectively, the quality circle has to be within the components of organizational structure. This structure may vary from one company to another but it is very important to have a regulatory framework (structure) for a quality circle that includes the following elements, indicated by Al-Sayd (2013):

Steering committee: The committee for designing and developing quality circle programs. This committee is composed of representatives of senior management, human resource development and the staff union.

The coordinator: An administrative officer from the middle management level that represents a link between the steering committee and the facilitator.

The assistant: Senior supervision officer/chief worker manage a maximum of 10 circles, usually from one department of quality control, production or training departments.

Circle leader: The leader of the circle may be one of the supervisors from the regular managerial level who will organize and manage events, identify topics, discuss technique and ensure participation for success.

Circle members: The circle members are production line workers who have to attend all meetings as much as possible and participate effectively in the group for making proposals and ideas.
Causes of the quality circles failure: Chaudhary and Yadav (2012) discussed some common causes of failure as follows: the five quality principles beginning with the letter $\mathrm{S}$ are not adopted which are the basic foundations of success when using quality circle. These principles are set out in Table 2:

- $\quad$ Poor staff morale, owing to authoritarian management and mistrust (Prasanna and Desai, 2011)

- Lack of training

- Inefficient leadership

- Lack of management support

Quality circles tools: Some of the scholars call quality circles as quality tools or quality improvement tools. Others call them statistical quality control tools or problem-solving tools. Charles (2012) asserts that the teams of quality circles use seven tools in collecting, summarizing and analyzing the quantitative data. Other tools are sometimes used such as brainstorming, proximity, graphical reports and question tools approach. Other tools that help the circle members to generate ideas can be summarized as follows.

Check sheets: Check sheets are used to collect data in an orderly manner. They are used to monitor or identify problems and explain their causes. In order to monitor the progress of solutions during application, these sheets can be designed in different forms and sizes. Members of the circle must be able to design them in the form and size that meet their needs.

The histogram: The histogram is a portrait graph that shows the distribution of data in categories to record the observations or frequencies that occurred within that category. Members of the circle are able to interpret the meaning of the histogram in different images to illustrate the deviations.

Scatter diagram: A scatter diagram is a graphical chart that examines the relationship between the causes and their consequences (the correlation between two variables). This tool is usually used by the quality circle team to determine the power of the relationship between the cause of the effect and its strength between one reason and another.

Graphs: This tool is used to show the phenomena and facts relevant to the problem. 
There are different types of presentation including the charts and pie chart which are the two most common means.

Parito diagrams: This is a tool to regulate errors, problems and defects and determine their priorities. The Parito diagram is based on the principle that $80 \%$ of the economic and service unit's problems are often the result of $20 \%$ of the reasons and that few reasons are responsible for most of the problems.

Cause and effect diagram: This is a demonstrative diagram to analyze the cause and effect of the problem. It is a graphical presentation of the underlying causes known as skeleton of the fish.

Control charts: These charts focus on the follow-up of specification standards doing measurement processes and making corrective decisions during the production process by examining samples of the process outputs. If these samples are within acceptable limits, the operation is advised to continue but if they are outside acceptable limits, the operation is stopped until the cause is known and addressed.

Uses of the quality circles: The lack of company management confidence in the staff and the insistence on absence of its role in it has created a conflict between quality improvement and cost reduction. But management alone is unable to integrate them to achieve customer satisfaction (Chaudhary and Yadav, 2012).

The concept of quality circle may be adopted for a variety of reasons including increasing the quality of production, participating in decision-making and working hard to satisfy customers. There is also, another use of quality circle that is to increase job satisfaction among employees and involving them in corporate policy decisions as well as to contribute to the generation of new ideas, reveal the potential of employees, thus, lead to a higher level of efficiency through product design by reducing the component parts of the product and reducing the time needed to assemble them. This is expressed by the achievement of higher productivity of the worker with improved quality of products at lower cost and higher profit (Shireen, 2014). The design process requires coordination and communication between the manufacturing activities and previous activities which is the work of the quality circle team to solve all technical and non-technical problems (Al-Azzawi and Khamis, 2011).

The quality circle is often allowed to choose its own goal and the idea behind its existence is to conduct the right training for employee's in order to make the worker able to detect quality problems that have not already been identified as well as the ability of the circle members to participate and follow-up. This is an advantage of quality circle as a tool for building a workforce and creating technical skills to prevent defects or reduce the spoilage of material during production, thereby improving its quality and have a significant effect on the productivity, cost reduction and achievement of greater profitability (Charles, 2012).

\section{MATERIALS AND METHODS}

The research was based on the inductive approach in explaining the research problem in the theoretical part. A case study approach was used in the practical part to analysis of the data collected by using the check lists to identify the causes of product defects as well as proofing the hypothesis. The general company for the automobile industry, Alexandria has many factories. One of these factories is the Saloon Cars Production Factory. This factory manufactures various models of automobiles and has many production lines including Teeba poduction line. The research data was collected from the records of Teeba production line for the month of June 2018. The Saloon Cars Production Factory was selected for the following reasons:

The importance of the products of this factory which is considered the only factory in the country. The company's readiness to cooperate at a high level to implement quality circles for the purpose of identifying the causes of defective units. The possibility to obtain the data to the extent appropriate to the nature of research. The product of Teeba saloon car model 2018 was selected because it has a long technological track where the production line comprises three main stations (car body conveyor, zero station, mechanical station $\mathrm{M}$, terminal $\mathrm{F}$ station) which give an opportunity for evaluation.

\section{RESULTS AND DISCUSSION}

Discussion of quality circles in practice: This part discusses the results related to the practical part of the research as follows:

Overview of the research sample: The general company for the automobile industry as one of the formations of the Ministry of Industry and Minerals has capital of $(216,340,000)$ Iraqi dinars. The company has many factories which manufacture various models of automobiles. Each factory is responsible for the implementation of plans and maintaining the quality level 
of products within the technical specifications. One of these factories the Saloon Cars Production Factory was chosen as a research sample. The data was collected from the records of one of the most important production line, Teeba saloon car for the month of June 2018.

Analysis of the examination system plan in the production line: This part highlights the analysis of the examination plan of the examination units deployed in the production line to identify how to check the parts and the product in process, ending with the completion of the finished product as well as the time of examination at each station for identifying weaknesses and strengths. The product examination plan consists of three individual units, parts examination, along the assembly stations examination and a final examination where product defects are detected and corrected.

\section{Product examination stages include}

First; examination of the metal, rubber and glass parts: The parts of all kinds are placed in the feeding unit of production lines (logistics) and the examination procedures include the verification of the number and validity. This is not a functional performance examination of the parts as it passed this stage in the country of origin.

Second; the continuous examination (along the production line): The product passes from the beginning of the production line (Zero station) to the end of the production line (F30) with a number of checks:

Body examination: Preparing and cleaning the body and make sure that there are no dimples and this is done by visual examination.

Checking the assembly of gearbox: In this stage the steering wheel, the group of the brake pipes, the fuel with the body as well as the fuel tank, the water container washers and the hose filling the fuel with the tank are checked by sight and touch.

T1-7 checking station: Here, assembly of the parts with the body is checked when the product in process (the body) passes through the stations and then these are subjected to a general check at the $\mathrm{T} 7$ station (the transition gate to the other stations) by sight.

T8-14 checking station: After examining assembly of the parts at the stations, a general check is conducted at the gate of station T. 14 by sight and touch.
Sub mechanical assembly checking stations: In this station the assembly of the parts with the engine is checked, including the gear box, the self-engine, the cooling compressor, the engine installation brackets with the body, belts, the shafts, the filling of the oils. The check is conducted by sight and touch using the incantation tool.

Mechanical assembly stations: In these stations the assembly of the engine with the body, the exhaust pipe, the arm of the change of speed, the rear axle, the set of front, rear suspension and tires are checked by touch and incantation tools.

Final assembly stations: In these stations the rear drum nuts are checked and making sure that the fuel pump, the engine water cooler with the hoses, the power steering pump hoses, air purifier hoses, heating hoses, battery base, radiator water tank, fuse base, front lights and front and rear seats are installed using the incantation tools by touch and sight as well as stations of filling water radiator and hydraulic and brake oil and water of washers and cooling gas.

Third; the final check (Finished Products): After the completion from the station F30, the product becomes complete then it passes a number of checking stations in order to conduct a functional test of the product to make sure of its functional performance and the required efficiency of these stations.

Lights and wheel alignment station: This station adjusts the corners of the rotation device using the balancing equipment and adjusts the corners of the set of headlights.

Speed test: By this test the brake device, the hand brake device, the convenience of the engine with the speed box and the transition from speed to another are tested.

Road test: The vehicle is checked on the road (track examination), to ensure the safety of engine operation, the appropriateness of speed transmissions and the absence of strange sounds. The suspension system, work of the brake and work of the hand brake are also, examined in a place dedicated to this type of examination.

Body underneath check: The connections of the brake pipes and the fuel pipes are checked for their non-perfusion and make sure that non-perfusion does not exist in the oil and fuel filters as well as checking the assembly of other parts. 
Int. Business Manage., 13 (5): 168-180, 2019

\begin{tabular}{lll} 
Table 3: Checking time for assembly stations & \\
\hline Checking time (min) & Checking site lobe & Checking the product \\
\hline 4 & Zero station end & Continuous checking \\
48 & Trim 14 station gate & Continuous checking \\
6 & Sub-M gate & Continuous checking \\
20 & M-19 station gate & Continuous checking \\
28 & F-30 station gate & Continuous checking \\
4 & Unit of balancing lights and wheels & Final checking \\
3 & Roll test unit & Final checking \\
15 & Road test unit & Final checking \\
5 & Body underneath checking unit & Final checking \\
15 & Non-power water impermeability unit & Final checking \\
10 & Touch up unit & Final checking
\end{tabular}

Table 4: Test time for each assembly station for the work-in-process product

\begin{tabular}{lrrl} 
& \multicolumn{2}{l}{ Time (min) } & \\
Test time/ & \multicolumn{1}{c}{----------------- } & \\
process time (\%) & Test & Station & Station name \\
20 & 4 & 20.36 & Zero \\
12 & 48 & 407.40 & TR 1-14 \\
22 & 6 & 27.52 & Sub-M \\
15 & 20 & 130.00 & M 15-19 \\
14 & 28 & 198.52 & Final \\
13 & 106 & 785.00 & Total \\
\hline
\end{tabular}

Water test: The water track is checked to make sure that it does not exudates inside the vehicle by using the shower tubes with a strong and suitable angle for $5 \mathrm{~min}$.

Final test: It is a thorough and quick test, in which the product (car) passes through a brightly lit place to see the luster and final touches and then sent to the delivery yards.

Overall test time: The technique used in the research sample to control the quality of the product is the technique of examination to determine the extent of conformity of the product to the predefined specifications to identify the defective products. This technique requires a number of examiners and tools necessary to achieve it, thus, leads to increased costs. So, the research has adopted the calculation of the total time of checking the semi-finished product through the assembly line stations to the last station in the production line and the calculation of the total time of checking the final product, excluding the examination of the initial parts, as shown in Table 3 .

In order to determine the causes of the increase in the time allocated to check the product, Table 4 is prepared to show the time of the check of each station to assemble the parts of the product. The time of the check is different between the stations, considering the number of parts and the complexity of the assembly processes inside the station. Table 4 shows the percentage of test time allocated to process time. The test time allocated to a finished product amounted to $52 \mathrm{~min}$. In order to calculate the percentage of time allocated to test the product to the total time of the product assembly stations, the following steps were adopted:
- Testing time allocated to work-in-process was 106 (min)

- Testing time allocated to a finished product was 52 (min)

- The total time of the assembly stations of the product was $785(\mathrm{~min})$

By dividing the total testing time $(106+52=158 \mathrm{~min})$ to the total time of the assembly stations $(785 \mathrm{~min})$, we found that the percentage of time allocated for testing the product, amounted to $20 \%$ of the assembly time. This indicated that the number of defective units at the assembly stations was high in spite of the high, evaluation represented by the check and test as well as the high repair costs. From the review of the reality of the quality control system in the factory research sample, it was found that:

The technique of control or quality control was conducted through checking or examination, i.e., to identify the defects of the product after their occurrence rather than its prevention or precluding them. The absence of using the techniques or tools of quality control by the employees or the departments concerned. The percentage of the time allocated for the test (continuous and final) compared to the total time of the operations within the aggregate stations amounted to $20 \%$. When analyzing the station time and the test time, we found the following:

Problems related to quality/high number of defective units, low product quality. Problems related to control, repeated defects and high repair hours of defective units. Cost problems and absence of optimum use of parts (raw materials). Problems of effectiveness, non-delivery on time and decrease in actual units sent to delivery yards compared to planned units. Accordingly, we noted that there was no contradiction between the low quality of the product and the increase in costs which led to low productivity. In order to identify product defects and determine the causes the quality circles will be applied.

Steps for quality circles: The work of quality circles is to identify, select and analyze the problem and then explain the appropriate solutions to it. The steps of quality circles taken were as follows: 
Identification of the problem: In this step, the problems are identified and then the problem with the first priority is chosen. The problem here is the increase in the defective units and the consequent low quality and increased cost.

Selection of the problem: The data concerning the problem was collected and arranged according to, its importance based on the check lists, in order to determine the causes for the low quality by reviewing the quality control unit's records of the product. Sixty samples were withdrawn from the production of the first week of June, 2018. The results are shown in Table 5.

The results of the research sample indicated that there were a large number of defects in a single product. Therefore, the team worked to arrange the defects according to, their frequency and importance. Table 6 showed a check list of assembly stations and types of defects distributed daily for each type of defects to help knowing the causes of defects and facilitate the process of determining the costs of repair of each defect. The important thing is to know the types of defects, their frequency and importance and whether the units produced within the limits of control or quality level or not. Therefore, the team of quality circles prepared a check list (or an audit list) to identify the defects their frequency and explain their causes.

Analysis of the results: The measurement of the product quality in the factory was done by categorizing the units into defective (unaccepted) and non defective (accepted) units. The accepted units were classified in Fig. 1 to accepted units with a very limited defect level with no defects of class (S), (P), (A) and (B) that is they were not influential with regard to customer satisfaction, so, they were called normal units. Units with the level of defect between the normal and ideal units were called good units. Other units with lower defect level than the target of the company were called ideal units. Figure 1 clearly showed that any product got a score of $(-50)$ was considered acceptable and represented the minimum level of quality and what got more than this score was

\begin{tabular}{|l|lc|}
\hline Hazardous units & & B, A, P, S \\
\hline Warning units & & B, A, P \\
\hline Ordinary units & & $(-50)$ C, B \\
\hline Good units & - & $(-45,0) C$ \\
\hline Ideal units & $\Downarrow$ & 0 \\
\hline
\end{tabular}

Fig. 1: The equality levels of produced units considered unacceptable and then unaccepted. Therefore, a search would be made on the causes of product defects on the basis of importance of defect by the adoption of

Table 5: No. of defects in the product

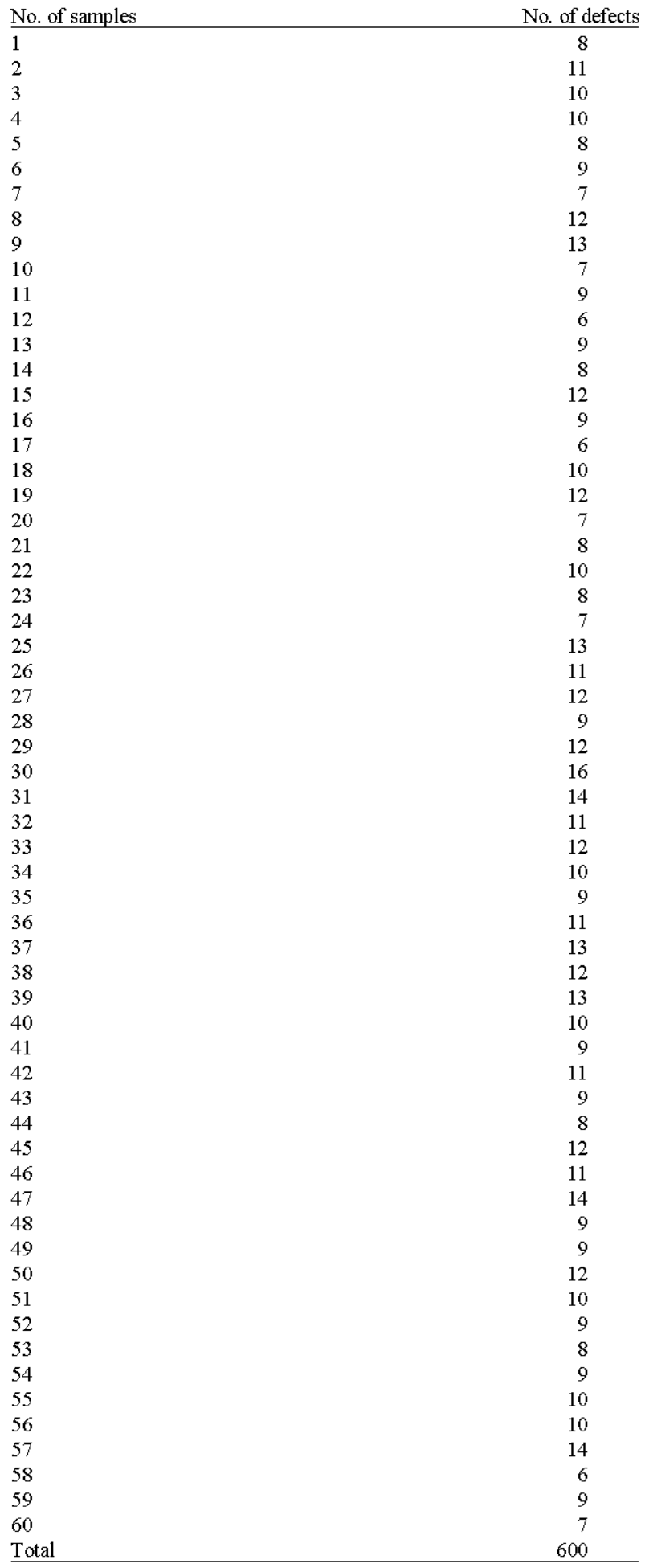

Prepared by the researchers depending on records of the quality control 
Int. Business Manage., 13 (5): 168-180, 2019

Table 6: A check list of product defects

\begin{tabular}{|c|c|c|c|c|c|c|c|}
\hline Defects/type of defects & Day 1 & Day 2 & Day 3 & Day 4 & Day 5 & Total & Importance \\
\hline \multicolumn{8}{|l|}{ Mechanical } \\
\hline Vent brake & 2 & 3 & 4 & 3 & 4 & 16 & $\mathrm{~s}$ \\
\hline Damage tire frame & 2 & 4 & 4 & 1 & 3 & 14 & $\mathrm{~s}$ \\
\hline Front suspension breakdown & 3 & 2 & 3 & 4 & - & 12 & A \\
\hline \multicolumn{8}{|l|}{ CFC end of production line } \\
\hline Tire incantation & 4 & 2 & 4 & - & 6 & 16 & $\mathrm{~s}$ \\
\hline Damage in the driver's seat screws & - & - & 8 & - & 5 & 13 & $\mathrm{~s}$ \\
\hline Incantation of suspension & 3 & 1 & 2 & 3 & 3 & 12 & A \\
\hline Cooling gas leakage & 3 & 3 & 2 & 2 & - & 10 & A \\
\hline Normalization of doors & 2 & 1 & 2 & 2 & 2 & 9 & A \\
\hline Damage in the radiator base screws & 2 & 1 & 1 & 3 & 2 & 9 & A \\
\hline Do not connect the plug of (warning sign) of seat belt & - & - & 2 & 2 & 4 & 8 & A \\
\hline Normalization of front lights & 7 & 5 & 8 & 4 & 6 & 30 & B \\
\hline Normalization of back light & 3 & 2 & 6 & 4 & 7 & 22 & B \\
\hline Normalization of front and rear bumper & 3 & 5 & 3 & 3 & 4 & 18 & B \\
\hline Normalization of front glass rubber adjacent with the body & 2 & 2 & - & 4 & 2 & 10 & B \\
\hline Lack of warning signs for children & - & 3 & 6 & 5 & 7 & 21 & $\mathrm{C}$ \\
\hline Lack of doors liner clamp & 2 & 4 & 4 & 6 & - & 16 & $\mathrm{C}$ \\
\hline \multicolumn{8}{|l|}{ Electrical } \\
\hline Fuel level gauge break down & 2 & - & 2 & 6 & 2 & 12 & $\mathrm{P}$ \\
\hline Brain failure & 4 & - & 2 & 2 & 3 & 11 & $\mathrm{P}$ \\
\hline Car horn not working & 4 & 2 & 2 & - & 2 & 10 & A \\
\hline Break down of break light & 5 & 2 & - & - & 2 & 9 & A \\
\hline Camera image deflection & 6 & 3 & 2 & 6 & 3 & 20 & B \\
\hline Back sensors not working & 4 & 2 & 2 & 4 & 4 & 16 & B \\
\hline Center lock not working & 5 & 2 & - & 3 & 4 & 14 & B \\
\hline Irregularity of windshield work & 2 & 4 & 4 & 4 & - & 14 & B \\
\hline Break down of rear trunk lamp & 5 & 3 & 7 & 2 & 3 & 20 & $\mathrm{C}$ \\
\hline Car interior lights not working & 4 & 5 & 3 & 4 & 2 & 18 & $\mathrm{C}$ \\
\hline \multicolumn{8}{|l|}{ Road } \\
\hline Vehicle deflection when using brakes & - & - & 2 & 8 & 2 & 12 & $\mathrm{~s}$ \\
\hline Sound in the engine & 6 & - & - & 4 & 2 & 12 & $\mathrm{P}$ \\
\hline Not connecting radiator join & - & 2 & 2 & - & 2 & 6 & $\mathrm{P}$ \\
\hline Very solid brake pedal & 4 & 2 & 4 & 6 & - & 16 & A \\
\hline Vibration in the steering & 4 & - & 2 & 2 & 6 & 14 & A \\
\hline Tough fuel pedal & 2 & - & 2 & 4 & 2 & 10 & A \\
\hline Tough gear stick & 2 & - & 2 & 2 & 4 & 10 & A \\
\hline Sound in the left rear axle & 2 & - & - & 2 & 4 & 8 & A \\
\hline Vibration and abnormal work of the engine & 2 & 3 & - & 2 & - & 7 & A \\
\hline \multicolumn{8}{|l|}{ Calibration } \\
\hline Calibration (adjustment) of the hand brake & - & 5 & 4 & 2 & 3 & 14 & A \\
\hline Clutch calibration & 1 & 1 & 2 & 5 & 2 & 13 & A \\
\hline \multicolumn{8}{|l|}{ Water leak } \\
\hline Water leak inside the vehicles/front door & - & - & 4 & 3 & 5 & 12 & A \\
\hline Trunk & 3 & 2 & 4 & - & 2 & 11 & A \\
\hline \multicolumn{8}{|l|}{ Painting and body } \\
\hline Color difference of bumper with the body & - & 4 & 2 & 3 & 2 & 11 & A \\
\hline Lack of glossiness & 4 & 1 & 3 & 2 & - & 10 & A \\
\hline Body damage/wing & 3 & 4 & 2 & 2 & - & 11 & B \\
\hline Body damage/driver's door & 1 & 2 & 4 & 1 & 2 & 10 & B \\
\hline Bonnet scratch supplement & - & 1 & 2 & 2 & - & 5 & $\mathrm{~B}$ \\
\hline Doors/scratch & - & 1 & 2 & - & - & 3 & B \\
\hline The presence of a simple crack in the body & 2 & 3 & 2 & 4 & 2 & 13 & $\mathrm{C}$ \\
\hline Retouching and cleaning the inside trunk & 3 & 2 & 2 & 3 & 2 & 12 & $\mathrm{C}$ \\
\hline
\end{tabular}

Prepared by the researchers depending on the product data of the quality control department

Table 7: Product defects frequency and repair costs

\begin{tabular}{|c|c|c|c|c|c|c|c|}
\hline \multirow[b]{2}{*}{ Categories/defects } & \multirow{2}{*}{$\begin{array}{l}\text { Safety } \\
\text { Class (S) }\end{array}$} & \multirow{2}{*}{$\begin{array}{l}\text { Stopping } \\
\text { Class (P) } \\
\end{array}$} & \multicolumn{4}{|c|}{ Performance and appearance } & \multirow[b]{2}{*}{ Total } \\
\hline & & & Class (A) & Class (B) & Class (C) & Class (D) & \\
\hline Frequency & 71 & 41 & 215 & 173 & 100 & - & 600 \\
\hline Costs (Iraqi dinar) & 271,959 & $1,817,376$ & 59,9670 & 22,51166 & 12,833 & - & $4,953,004$ \\
\hline
\end{tabular}

check lists which identify the causes of defects after the determination of each class of defects. Table 7 showed the frequency and cost of the defects for each item.
Defects of class (S) (Safety and Security) got a score of (-120) (Degree of Failure). They are known with all defects or errors resulting from not monitoring the vehicle 
Int. Business Manage., 13 (5): 168-180, 2019

Table 8: Causes of the product defects related to safety and security

\begin{tabular}{|c|c|c|c|c|c|c|}
\hline \multirow{2}{*}{$\begin{array}{l}\text { Type of defect } \\
\text { safety and security }\end{array}$} & \multirow{2}{*}{$\begin{array}{c}\text { No. of } \\
\text { observed defects }\end{array}$} & \multirow{2}{*}{$\begin{array}{c}\text { Costs of repairing } \\
\text { (Iraqi dinar) }\end{array}$} & \multicolumn{4}{|c|}{ Causes of defects } \\
\hline & & & Parts & Employment & Working methods & Equipment and machinery \\
\hline Vent brake & 16 & 10,000 & - & 10 & - & 6 \\
\hline Damage tire frame & 14 & 227,500 & - & 14 & - & \\
\hline Tire incantation & 16 & 3,334 & - & 16 & - & \\
\hline Damage in the driver's seat screws & 13 & 21125 & - & 13 & - & \\
\hline Vehicle deflection when using brakes & 12 & 10,000 & - & 6 & - & 6 \\
\hline Total & 71 & 271,959 & - & 59 & - & 12 \\
\hline
\end{tabular}

Table 9: Causes of product defects related to stopping

\begin{tabular}{|c|c|c|c|c|c|c|}
\hline \multirow{2}{*}{$\begin{array}{l}\text { Type of defect } \\
\text { stopping class }(\mathrm{P})\end{array}$} & \multirow{2}{*}{$\begin{array}{l}\begin{array}{l}\text { No. of } \\
\text { observed defects }\end{array}\end{array}$} & \multirow[b]{2}{*}{ Costs of repairing } & \multicolumn{4}{|c|}{ Causes of defects } \\
\hline & & & Parts & Employment & Working methods & Machines and equipments \\
\hline Fuel level gauge malfunction & 12 & 7,500 & & 12 & - & - \\
\hline Brain failure & 11 & $1.794,375$ & 11 & & - & - \\
\hline Sound in the engine & 12 & 15,000 & 2 & 10 & - & - \\
\hline Not connecting radiator join & 6 & 500 & & 6 & - & - \\
\hline Total & 41 & $1.817,375$ & 13 & 28 & - & - \\
\hline
\end{tabular}

Table 10: Causes of product defects related to performance and appearance class (A)

\begin{tabular}{|c|c|c|c|c|c|c|}
\hline \multirow[b]{2}{*}{$\begin{array}{l}\text { Type of defect } \\
\text { Performance and appearance class (A) }\end{array}$} & \multirow[b]{2}{*}{$\begin{array}{l}\text { No. of } \\
\text { observed defects }\end{array}$} & \multirow[b]{2}{*}{$\begin{array}{l}\text { Costs of repairing } \\
\text { (Iraqi dinar) }\end{array}$} & \multicolumn{4}{|c|}{ Causes of defects } \\
\hline & & & Parts & EmploymentWorking & g methods & Machines and equipments \\
\hline Front suspension breakdown & 12 & 7,500 & & 12 & - & -2 \\
\hline Incantation of suspension & 12 & 1,000 & & 12 & - & - \\
\hline Cooling gas leak & 10 & 8,334 & & 7 & - & 3 \\
\hline Normalization of doors & 9 & 11,250 & & 9 & - & - \\
\hline Screw damage in the radiator base & 9 & 12,750 & & 9 & - & - \\
\hline Not connecting the plug (warning sign) seat belt & 8 & 3,334 & & 8 & - & - \\
\hline Horn failure & 10 & 4,167 & & 10 & - & - \\
\hline Brake light failure & 9 & 750 & & 9 & - & - \\
\hline Tough brake pedal & 16 & 10,000 & & 12 & - & 4 \\
\hline Vibration in the steering wheel & 14 & 8,750 & 14 & & - & - \\
\hline Tough vehicle fuel pedal & 10 & 1,250 & & 10 & - & - \\
\hline Tough gear stick & 10 & 1,667 & & 10 & - & - \\
\hline Sound in left rear axle & 8 & 6,667 & & 8 & - & - \\
\hline Vibration and abnormal work of motor & 7 & 4,375 & 3 & 4 & - & - \\
\hline Calibration (adjustment) of the hand brake & 14 & 1,167 & & 14 & - & - \\
\hline Calibration of the clutch & 13 & 1,083 & & 13 & - & - \\
\hline Water leak inside the vehicle's front door & 12 & 2,500 & & 12 & - & - \\
\hline Trunk & 11 & 2,292 & & 11 & - & - \\
\hline Color difference of pumper with the body & 11 & 4,584 & 11 & & - & - \\
\hline Lack of gloss & 10 & 506,250 & & 10 & - & - \\
\hline Total & 215 & 599,670 & 28 & 180 & - & 7 \\
\hline
\end{tabular}

or damage of the vehicle which leads to damage to the driver or passengers or surrounding people such as damage or failure to install the screw of tiers or the safety belts are not working etc. The results shown in the Table 8 indicated that the contribution of labor (workers) to the occurrence of product defects and their costs amounted to $83 \%$ while the contribution percentage of equipment and machinery amounted to $17 \%$ because of the irregular operation of the air discharge system of the brake system and not filling it with brake oil.

Defects of class (P) (stopping) got a score of (-100) degree of deficiencies. They are known with all the defects that make driving a vehicle impossible for such causes as: hydraulic, mechanical or electrical causes, leakage of dangerous liquids and other defects appear in the test. The results of the Table 9 indicated that the percentage of contribution of the parts (raw materials) in the occurrence of product defects and their costs amounted to $32 \%$ due to the such manufacturing causes as non-tightening of screws to fix the front teeth of the crankshaft and non-tightening the belts. Further, the contribution percentage of employees to the occurrence of product defects amounted to $68 \%$ of the stopping total defects.

Performance and appearance class (A) defects got a score of $(-30)$, if it was functional and $(-20)$, if it was related to the appearance (Table 10). They were defined as defects that needed to be repaired immediately without delay because they were influential and included such defects as: defects that may appear in future potentially or regularly obvious defects in appearance or performance noise caused by mechanical or body parts and defects appear in a short time lead to damage the vehicle. 
Int. Business Manage., 13 (5): 168-180, 2019

Table 11: Causes of the product defect related to performance and appearance class (B)

\begin{tabular}{|c|c|c|c|c|c|c|}
\hline \multirow[b]{2}{*}{$\begin{array}{l}\text { Type of defect } \\
\text { Performance and appearance class (B) }\end{array}$} & \multirow[b]{2}{*}{$\begin{array}{l}\text { No. of } \\
\text { observed defects }\end{array}$} & \multirow[b]{2}{*}{$\begin{array}{l}\text { Costs of repairing } \\
\text { (Iraqi dinar) }\end{array}$} & \multicolumn{4}{|c|}{ Causes of defects } \\
\hline & & & Parts & Employment & Working methods & Machinesandequipments \\
\hline Normalization of front head light & 30 & 6,250 & 30 & - & - & - \\
\hline Normalization of back light & 22 & 2,750 & 22 & - & - & - \\
\hline Normalization of front and back bumpers & 18 & 11,250 & 5 & 13 & - & - \\
\hline Normalization of front glass rubber with the buddy & 10 & 1,250 & 5 & - & 5 & - \\
\hline Camera image deflection & 20 & 4,167 & & 20 & - & - \\
\hline Return back sensor not working & 16 & 6,666 & & 16 & - & - \\
\hline Center lock not working & 14 & $2,105,833$ & 7 & 7 & - & - \\
\hline Work irregularity of windshield wipers & 14 & 1,750 & - & 14 & - & - \\
\hline Damaged body/wing & 11 & 13,750 & - & - & 11 & - \\
\hline Damaged body/driver's door & 10 & 12,500 & - & 4 & 6 & - \\
\hline Bonnet scratch supplement & 5 & 53,125 & - & 2 & 3 & - \\
\hline Scratch/doors & 3 & 31,875 & - & 1 & 2 & - \\
\hline Total & 173 & $2,251,166$ & 69 & 77 & 27 & - \\
\hline
\end{tabular}

Table 12: Causes of product defects related to performance and appearance class (C)

Type of defect

Causes of defects

\begin{tabular}{|c|c|c|c|c|c|c|}
\hline \multirow{2}{*}{$\begin{array}{l}\text { Performance and appearance } \\
\text { class (C) }\end{array}$} & \multirow{2}{*}{$\begin{array}{l}\text { No. of observed } \\
\text { defects }\end{array}$} & \multirow{2}{*}{$\begin{array}{l}\text { Cost of repairing } \\
\text { (Iraqi dinar) }\end{array}$} & \multicolumn{4}{|c|}{ - } \\
\hline & & & Parts & Employment & Working methods & Machines and equipments \\
\hline Lack of warning signs for children & 21 & 1,750 & - & - & 21 & - \\
\hline Lack of lining clamps of the doors & 16 & 1,333 & - & - & 16 & - \\
\hline Trunk light failure & 20 & 1,667 & & 20 & - & - \\
\hline Car room light failure & 18 & 6,000 & 9 & 9 & - & - \\
\hline Existence of a simple crack in the body & 13 & 1,083 & & - & 13 & - \\
\hline Inside trunk retouching and cleaning & 12 & 1,000 & 12 & - & - & - \\
\hline Total & 100 & 12,833 & 21 & 29 & 50 & - \\
\hline
\end{tabular}

The analysis showed that the equipment and tools represented the most insignificant percentage which contributed to the occurrence of $3 \%$ of product defects due to non-maintenance of the unloading and filling device. The percentage of the contribution of the parts in the occurrence of defects and their cost amounted to $13 \%$ which was due to the lack of air quantity in the tire, tire pressure or balance and lack of fuel or one of the plugs or that the socket were not installed correctly while the percentage of the contribution of labor in the occurrence of product defects amounted to $84 \%$.

Performance and appearance class (B) defects got a score of $(-20)$, if the defects were related to functions and $(-10)$, if they were related to appearance (Table 11). These defects were defined as significant defects discovered by customers and needed to be repaired again including defects that would damage the parts. These defects can undoubtedly be seen by customers and require repair.

The study found that the methods of work were the least influential, so that, the percentage of their contribution to the occurrence of product defects amounted to $16 \%$. This was due to inadequate storage and methods of transport of the body starting from the storage method in the yards through the preparation of the body and ending with the injury of the body in the production line due to negligence of workers. While, the causes of scratches (friction from the inside) were because transport to long distances. The percentage of the contribution of the parts in the occurrence of product defects amounted to $40 \%$ which were manufacturing defects represented by the following:

- Inaccuracy of the measurements of the installing places of the front hand lights to get lights leveling with the front wings and bumper

- Inaccuracy measurements of installing places of back lights (manufacturing) because of the mold of the light

Performance and appearance class (C) defects got a score of $(-10)$ or $(-5)$. They were defined as defects seen by customers and might not need to be repaired because they did not damage the parts. The results of Table 12 indicated that the percentage of the contribution of the parts in the occurrence of product defects and their costs amounted to $21 \%$. They were due to (not installing the light switch correctly and the friction of the parts together). While the percentage of the contribution of workers amounted to $29 \%$ and the percentage of the contribution of working methods in the occurrence of defects reached $50 \%$. These belong to the following causes: the movement of materials (storage) was not controlled. One supplier was almost relied on and 
transportation was improper as well as storage is inadequate. Class (D) defects did not get any score, i.e., no change in the estimates. These defects may be found by specialized customers or experts in the field of specialization. This type of defects does not affect the satisfaction of customers.

\section{CONCLUSION}

The research has reached many important conclusions. These are: when the check lists were used in the analysis, it was found that employees were the most influential factor in the low level of quality and the consequent increase in costs so that the contribution percentage of the employees in the occurrence of defects amounted to $62 \%$, i.e. (373) defects of the total (600) defects). This was due to the following causes:

Employees are not involved or their proposals regarding the problems solving are not accepted which have negative effects including lack of motivation, low level of loyalty, non-commitment etc. Lack of the administration's interest in training programs. The workers are not involved in the production line for training courses, if any, whether inside or outside the company. Lack of awareness of the departments involved in the importance of using at least traditional quality control tools or statistical control tools.

Lack of adequate working conditions, as well as other work pressures. The analysis indicated that the parts (components of the product) and the body were less effective causes of product defects, representing $22 \%$ of the total defects. This was due to the following causes: All parts were not checked at the entry of the store, as well as some of them were electrical and could not be sure of their functional performance only when were used such as lights, brain and others.

Some rubber parts were subject to damage; due to poor storage. Most of the defects of the body resulting from transport, whether scratches or damages or frictions but the other defects of the body were manufacturing in nature. The analysis also showed that the working methods contributed by $13 \%$ of the total defects and they were due to: methods of storage of the bodies in the storage area and the equipment used in the unloading and transfer of bodies. The bodies in the preparation stage are stored without leaving spaces between them. Lack of scheduling production. Lack of a description or a technological course of the (30) assembly stations. It is clear from the use of check lists that machines and equipment were the least influential factor which accounted for $3 \%$ of total product defects. This was due to the aging of the production line equipment as well as lack of interest in maintenance.. The total costs of repair shown in Table 7 for the sample size were $4,950,000$ dinar which contributed to the low profitability of the product at a rate of 82,500 dinar as well as the other costs incurred by the company due to non-delivery on time.

Significance statement: The research is an important attempt to apply the quality circles technique in the car production industry. It provides the quality control department with the quality circles technique and its tools to analyze the causes of spoilage during assembly operations in order to avoid them by helping management to identify the influencing causes on quality from the entry of components of the product to the logistic department until the ending stage of production line. Finally, the research contributes to improving the quality level, reducing defects or mistakes and delivery the product to the sales yards on the specified time.

\section{RECOMMENDATIONS}

The research reached many important recommendations. These are: the level of employee's competency should be raised through the establishment of training programs within the company or outside it to address the lack of effective skills of employees. The factory management should motivate employees to reach their maximum potential and abilities by evaluating what they offer. There is a need to activate the quality management department in the company, apply the quality control tools and focus on the importance of these tools and their role in solving problems. The department of planning should prepare the scheduling of the requirements of raw materials. All transport requirements should be provided including lifting equipment, plastic separators between bodies and specialized transport vehicles. Preventive maintenance programs for the production line equipment should be applied to ensure no sudden stop.

\section{REFERENCES}

Abo-Alhol, T.R., M.Y. Ismail, S.M. Sapuan and M.M. Hamdan, 2006. Effects of quality circle participation on employee perception and attitude in five Malaysian companies. J. Sci. Ind. Res., 65: 970-976. 
Al-Azzawi, M.A.W. and A.M. Khamis, 2011. Japanese Manufacturing Systems and Just-in-Time Production System. 1st Edn., Ithraa Publishing \& Distribution, Amman, Jordan.

Al-Sayd, T.M.K., 2013. Total Quality Standards (Management, Statistics, Economics). 1st Edn., Dar Osama for Publishing and Distribution, Amman, Jordan.

Blocher, E.J., D.E. Stout and G. Cokins, 2010. Cost Management: A Strategic Emphasis. 5th Edn., McGraw-Hill Education, New York, USA., ISBN: 978-0-07-352694-2, Pages: 961.

Charles, J., 2012. Quality Circles: A Handbook for QC facilitators, QC Leaders and Members. Coal India, Kolkata, India,

Chaudhary, R. and L. Yadav, 2012. Impact of quality circle towards employees \& organization a case study. IOSR. J. Eng., 2: 23-29.
Gaikwad, V.V. and A.V. Gaikwad, 2009. Quality circle as an effective management tool: A case study of Indira College of Engineering and Management Library. Proceeding of International Conference on Academic Libraries, October 5-8, 2009, Delhi University Library System, University of Delhi (North Campus) Delhi, India, pp: 650-653.

Kaplana, K. and C. Hymavathi, 2013. Understanding and managing quality circles: A theoretical perspective. Intl. J. Res. Manage. Sci., 1: 24-33.

Prasanna, N.K.K. and T.N. Desai, 2011. Quality circle implementation for maintenance management in petrochemical industry. J. Eng. Res. Stud., 2: 155-162.

Shantanu, W. and S. Kulkarni, 2013. Quality circle to improve productivity. Intl. J. Eng. Res. Appl., 3: 814819.

Shireen, N., 2014. Quality circle: A fundamental unit of increase profitability. Intl. J. Manage. Commerce Innovations, 2: 30-34. 